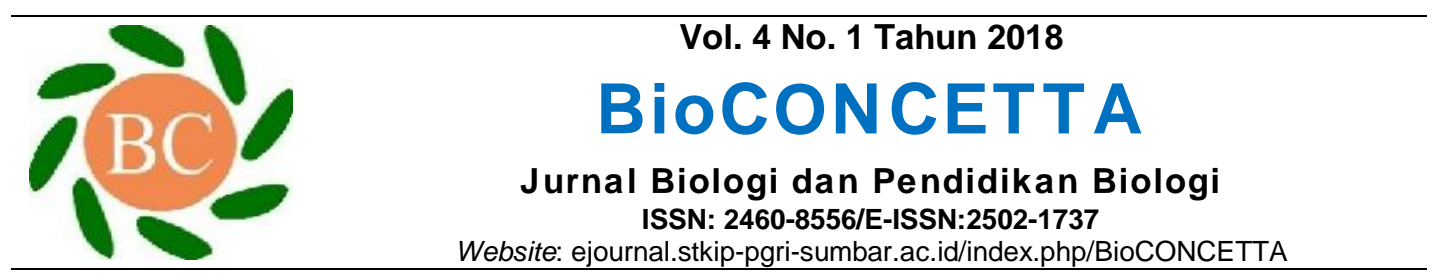

\title{
Jenis-jenis Plankton pada Danau Bekas Tambang Batu Bara Desa Pangkalan Riau
}

Nova Muryani*, Nofrita, dan Izmiarti

Jurusan Biologi FMIPA Universitas Andalas, Padang,

Jl. Limau Manis, Pauh, Limau Manis, Pauh, Kota Padang, Sumatera Barat (25163) Indonesia

E-mail: novamuryani@yahoo.co.id

\section{Info Artikel}

Sejarah Artikel

Diterima:

31 Juli 2018

Disetujui:

30 Agustus 2018

Dipublikasikan:

31Agustus 2018

\section{Kata Kunci:}

plankton, danau,

tambang,batu bara

Keywords:

plankton, lake,

mined,coal

\begin{abstract}
Abstrak
Penelitian ini bertujuan untuk mengidentifikasi jenis-jenis plankton yang mampu hidup pada danau bekas tambang batu bara. Pengambilan sampel dilakukan secara purposive sampling pada tiga stasiun dengan tiga kali ulangan. Sampel plankton di koleksi menggunakan net plankton no 25. Pengambilan sampel dilakukan pada bulan april 2018. Total plankton yang didapatkan sebanyak 23 spesies, 14 famili dan 5 kelas. Kelas terbanyak yang ditemukan adalah kelas Bacillariophyceae (7 family, 15 spesies). Spesies terbanyak yang ditemukan adalah Cylindrotheca closterium, Closterium idiosporum, Nitzschia longissima, Cosmarium formulosum dan Frustulia saxonica.
\end{abstract}

\begin{abstract}
This study aims to identify plankton that live at the coal mined lake. Sampling using purposive sampling on three stations with three repetitions. Samples of plankton collected using net plankton no 25 . This study was april 2018. A total of 23 species plankton were identified from 14 families, 5 classes. The highest family composition is Bacillariophyceae ( 7 families, 15 species). The most common species found are Cylindrotheca closterium, Closterium idiosporum, Nitzschia longissima, Cosmarium formulosum, and Frustulia saxonica.
\end{abstract}




\section{PENDAHULUAN}

Indonesia merupakan salah satu produsen batu bara terbesar di dunia. Menurut BP Statictical Review of world Energy 2017, Indonesia berada pada urutan kelima setelah China, Amerika Serikat, Australia dan India sebagai negara penghasil batu bara terbesar di dunia. Pada tahun 2016 Indonesia menghasilkan batu bara sebanyak 255,7 juta ton dengan cadangan batu bara yang dimiliki Indonesia adalah sebanyak 28.017 juta ton. Kegiatan pertambangan batu bara memberikan dampak yang signifikan terhadap penurunan kualitas lingkungan, terutama tanah, air dan udara. Sistem penambangan batu bara yang biasa digunakan adalah dengan penggerukan Top Soil,kemudian peledakan lapisan tanah sampai ditemukan sumber batu bara. Sehingga panambangan dengan sistem tersebut selalu menimbulkan kolong bekas tambang yang menyerupai sebuah danau.

Kabupaten Kuantan Singingi merupakan salah satu kabupaten di Provinsi Riau yang perekonomian masyarakatnya didominasi oleh pertanian, peternakan, perikanan dan industri pertambangan. Kuantan
Singingi memiliki cadangan batu bara sekitar 98.056.452 ton dengan luasan areal pertambangan 143.215,75 hektar. Areal pertambangan terluas berada di Kecamatan Logas Tanah Darat, yaitu seluas 112.800 hektar dengan jumlah cadangan 33.272 .970 ton. Jumlah tersebut masih kecil bila dibandingkan dengan cadangan batu bara di Pangkalan Ibul Kecamatan Pucuk Rantau yang teridentifikasi sebanyak 35.000.000 ton (Kurnia, 2013).

Di Desa Pangkalan, Pucuk Rantau, Kabupaten Kuantan Singingi, Riau terdapat danau bekas tambang batu bara. Danau tersebut terletak di kawasan perkebunan kelapa sawit. Keberadaan perkebunan kelapa sawit disekitar danau memungkinkan masuknya nutrien sisa pupuk dan peptisida yang dapat menyebabkan pengkayaan nutrien berupa fosfat dan nitrogen pada danau. Menurut ACI Indonesia (2005) pupuk organik yang mengandung fosfat dan nitrogen dapat memperbaiki standar kualitas air, sumber nutrisi bagi pertumbuhan plankton dan menekan angka kematian plankton.

Istilah plankton pertama kali dikenalkan oleh Victor Hensen pada 
tahun 1887, berasal dari bahasa Yunani yang artinya mengembara. Plankton adalah organisme yang terapung atau melayang-layang didalam air. Pergerakan dari plankton relatif pasif, sehingga selalu terbawa oleh arus air. Plankton merupakan salah satu komponen utama yang penting dalam perairan. Plankton menjadi makanan bagi sejumlah konsumen dalam rantai makanan dan jaring makanan (Sachlan, 1982).

Danau bekas tambang adalah ekosistem yang minim akan bahan organik. Rendahnya nilai $\mathrm{pH}$ dan tingginya kandungan logam berat menyebabkan sedikitnyaorganisme yang mampu hidup dan berkembang di lokasi tersebut. Minimnya bahan organik pada danau bekas tambang disebabkan tidak adanya aliran air masuk maupun keluar dari danau bekas tambang. Sumbangan bahan organik hanya berasal dari vegetasi sekitaran danau. Di Danau Hijau Desa Pangkalan, Kecamatan Pucuk Rantau, Kabupaten Kuantan Singing, Riau sumbangan bahan organik juga diberikan oleh sisa pupuk dan pestisida yang berasal dari perkebunan kelapa sawit sekitar danau. Hal ini menarik untuk dikaji untuk mengetahui apa saja jenis-jenis plankton yang mampu hidup pada danau bekas tambang tersebut.

\section{BAHAN DAN METODE}

Penelitian ini dilakukan pada bulan April 2018. Penelitian dilakukan di Danau Hijau bekas tambang batu bara Desa Pangkalan, Pucuk Rantau, Kabupaten Kuantan Singingi, Riau. Sampel plankton diambil dilapangan, selanjutnya di identifikasi dan dilanjutkan dengan analisa data di Laboratorium Riset Ekologi Hewan, Jurusan Biologi, Fakultas Matematika dan Ilmu Pengetahuan Alam.

Metode yang digunakan pada penelitian ini adalah metode survey denganteknik pengambilan sampel Purposive Sampling. Stasiun pengambilan sampel terdiri dari 3 stasiun yang ditentukan berdasarkan rona lingkungan di sekeliling danau. Sampel air danau hijau diambil sebanyak $100 \mathrm{~L}$ dengan metode timba dan disaring menggunakan plankton net no 25. Pengulangan dilakukan sebanyak 3 kali pada setiap stasiun. Sampel air yang tersaring dimasukkan ke dalam botol film kemudian diawetkan dengan formalin $4 \%$. 
Sampel plankton diambil individunya dan dikelompokkan sebanyak $1 \mathrm{ml}$ diamati setetes demi berdasarkan kriteria $* * *=$ Banyak setetes.Pengamatan plankton $(100-150 \mathrm{Ind} / \mathrm{mL}), * *=$ Sedang $(51-100$ menggunakan mikroskop dengan Ind $/ \mathrm{mL}$ ), dan $*=$ Sedikit 1-50 Ind $/ \mathrm{mL}$ ). perbesaran 10 x 40 dan 10 x 60. Untuk Adapun stasiun pengambilan sampel di identifikasi plankton digunakan Danau Hijau bekas tambang batu bara di beberapa buku panduan diantaranya Desa Pangkalan, Pucuk Rantau, Yamaji (1980), Prescott (1979), Bold Kabupaten Kuantan Singingi, Riau dan Wynne (1985) dan Pascher (1986). dapat dilihat pada Gambar 1.

Setiap spesies di hitung jumlah

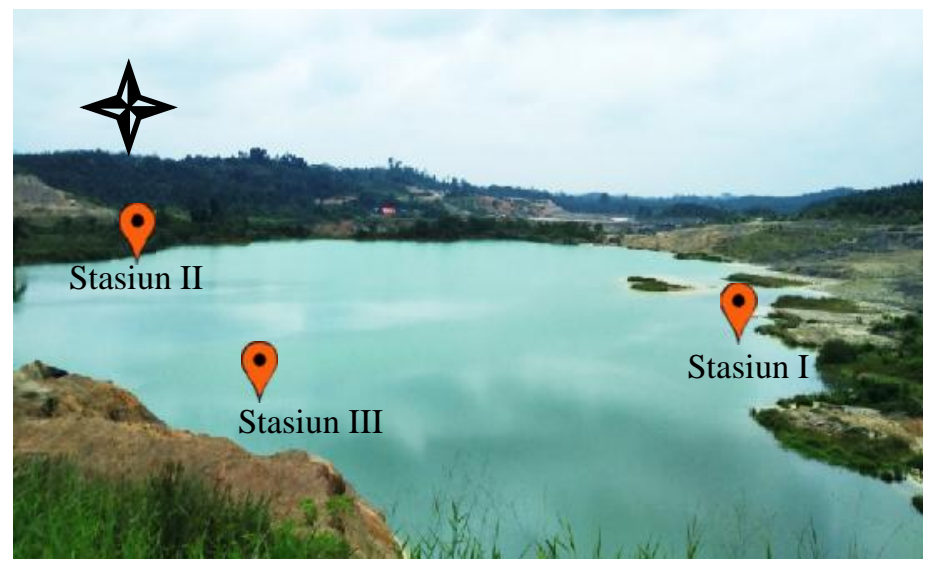

Gambar 1. Lokasi penelitian di danau hijau bekas tambang batu bara. Stasiun I dengan daerah litoral danau hijau yang bagian pinggirnya berupa vegetasi kelapa sawit berumur 3 tahun. Stasiun II dengan daerah litoral danau hijau yang bagian pinggirnya berupa vegetasi kelapa sawit berumur 5 tahun, dan stasiun III dengan daerah litoral danau hijau yang bagian pinggirnya berupa vegetasi kelapa sawit berumur $>10$ tahun.

\section{HASIL DAN PEMBAHASAN}

Plankton yang ditemukan di

Danau Hijau bekas tambang batu bara di

Desa Pangkalan, Pucuk Rantau,

Kabupaten Kuantan Singingi, Riau terdiri dari 23 spesies. Spesies yang ditemukan tergolong kedalam 5 kelas dan 14 family. Kelas yang didapatkan adalah Bacillariophyceae (7 family, 15 spesies), Chlorophyceae(1family, 1 spesies), Cyanophyceae(2family, 2 spesies),Zignematophyceae (2 family, 3 
spesies),Monogonata (2 family, 2 ditumbuhi makrofita akuatik dan spesies) dapat dilihat pada (Tabel 1). perkebunan kelapa sawit berumur 3

Jumlah jenis plankton yang tahun ditemukan plankton sebanyak 21 ditemukan dimasing-masing stasiun jenis (12 family, 4 kelas) (lihat Tabel 1). danau memiliki perbedaan. Pada stasiun I dengan kondisi pinggir danau

Tabel 1. Jenis-Jenis Plankton yang Ditemukan di Danau Bekas Tambang Batu Bara Desa Pangkalan Riau

\begin{tabular}{|c|c|c|c|c|}
\hline \multirow{2}{*}{ No. } & \multirow{2}{*}{ KELAS/Family/Spesies } & \multicolumn{3}{|c|}{ Jumlah Individu/ ml } \\
\hline & & Stasiun I & Stasiun II & Stasiun III \\
\hline \multicolumn{5}{|c|}{ BACILLARIOPHYCEAE } \\
\hline & Amphipleuraceae & & & \\
\hline 1 & Frustulia rhomboids & $*$ & $*$ & $*$ \\
\hline \multirow[t]{2}{*}{2} & Frustulia saxonica. & $* *$ & $* *$ & $*$ \\
\hline & Bacillariaceae & & & \\
\hline 3 & Cylindrotheca closterium & $* * *$ & ** & $* *$ \\
\hline 4 & Nitzschia longissima & $* *$ & $*$ & $*$ \\
\hline 5 & Nitzschia palea & $*$ & & \\
\hline \multirow[t]{2}{*}{6} & Nitzschia amphibian & $*$ & $*$ & \\
\hline & Cymbellaceae & & & \\
\hline \multirow[t]{2}{*}{7} & Cymbella affinis & $*$ & & \\
\hline & Diploneidaceae & & & \\
\hline \multirow[t]{2}{*}{8} & Diploneis puella & $*$ & & \\
\hline & Eunotiaceae & & & \\
\hline \multirow[t]{2}{*}{9} & Eunotia bilunaris & $*$ & & \\
\hline & Fragilariaceae & & & \\
\hline 10 & Fragilaria capucina & $*$ & & \\
\hline 11 & Fragilaria intermedia & $*$ & & \\
\hline \multirow[t]{2}{*}{12} & Fragilaria virescens & $*$ & & $*$ \\
\hline & Pinnulariaceae & & & \\
\hline 13 & Pinnularia moralis & $*$ & & \\
\hline 14 & Pinnularia tabellaria & $*$ & $*$ & \\
\hline 15 & Pinnularia viridis & $*$ & * & \\
\hline \multicolumn{5}{|c|}{ CHLOROPHYCEAE } \\
\hline \multicolumn{5}{|c|}{ Scenedesmaceae } \\
\hline 16 & Scenedesmus quadricauda & & & $*$ \\
\hline \multicolumn{5}{|c|}{ CYANOPHYCEAE } \\
\hline \multicolumn{5}{|c|}{ Oscillatoriaceae } \\
\hline \multirow[t]{2}{*}{17} & Lyngbya & & & $*$ \\
\hline & Rivulariaceae & & & \\
\hline 18 & Rivularia & $*$ & & \\
\hline \multicolumn{5}{|c|}{ ZIGNEMATOPHYCEAE } \\
\hline & Closteriaceae & & & \\
\hline 19 & Closterium dianae & * & & * \\
\hline \multirow[t]{2}{*}{20} & Closterium idiosporum & $* * *$ & $* *$ & $* *$ \\
\hline & Desmidiaceae & & & \\
\hline 21 & Cosmarium formulosum & $* *$ & $* *$ & \\
\hline \multicolumn{5}{|c|}{ MONOGONATA } \\
\hline \multirow{3}{*}{22} & Brachionidae & & & \\
\hline & Brachionus quadridentatus & $*$ & & $*$ \\
\hline & Lecanidae & & & \\
\hline \multirow[t]{2}{*}{23} & Lecane flexilis & $*$ & & \\
\hline & Jumlah Spesies & 21 & 9 & 10 \\
\hline
\end{tabular}


Pada stasiun II dengan kondisi pinggir danau ditumbuhi kelapa sawit yang berumur 5 tahun ditemukan plankton sebanyak 9 jenis (5 family, 2 kelas) (lihat Tabel 1). Pada stasiun III dengan kondisi pinggir danau ditumbuhi kelapa sawit yang berumur lebih dari 10 tahun ditemukan plankton sebanyaak 10 jenis (7 family, 5 kelas) dapat dilihat pada (Tabel 1). Jumlah spesies plankton yang ditemukan di Danau Bekas Tambang Batu Bara Desa Pangkalan Riau adalah 23 spesies. Jumlah spesies plankton tersebut lebih banyak dibandingkan dengan penelitian Nurwisma (2017) di Danau Biru Sawahlunto Sumatera Barat. Perbedaanjumlah plankton yang ditemukan di danau bekas tambang batu bara dipengaruhi oleh umur danau dan kondisi ekosistem danau.Seiring pertambahan usia danau yang semakin tua, karakteristik limnologis danau bekas tambang semakin menyerupai habitat alami danau sehingga mampu dihuni oleh lebih banyak jenis plankton.

Kelas yang terbanyak ditemukan di Danau Hijau bekas tambang adalah dari kelas Bacillariophyceae (7 familiy, 15 spesies). Kelas Bacillariophyceae merupakan kelompok fitoplankton yang banyak dijumpai diperairan. Kelas Bacillariophyceae mampu beradaptasi dengan baik dan berkembang dengan cepat. Hal ini sesuai dengan pernyataaan Raymont (1984) bahwa kelas Bacillariophyceae mampu berkembang dengan cepat kurang dari 10 jam.

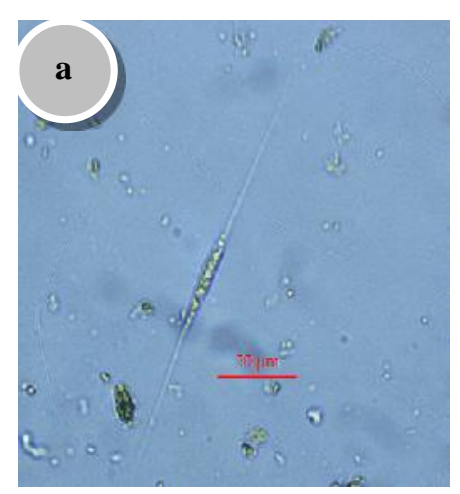

Gambar2.

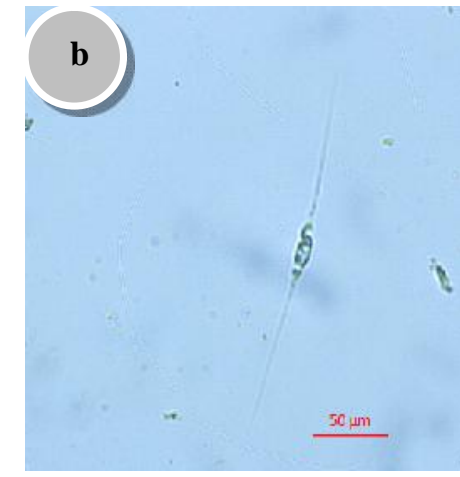

(a) Cylindrotheca closterium

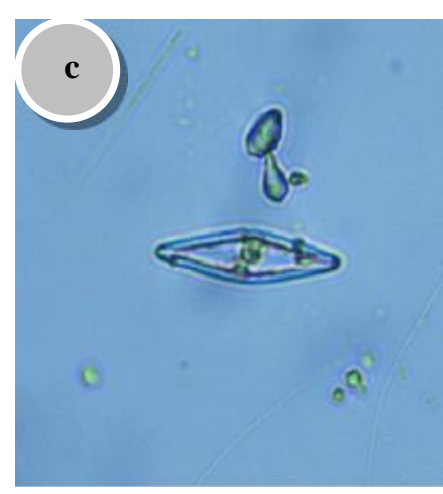

dan (b) Nitzschia longissimadariFamilyBacillariaceae, (c) Frustulia saxonicadari familyAmphipleuraceae. Ketiga spesises dari kelas Bacillariophyceae ini banyak ditemukan pada danau bekas tambang. 
Perbedaan jumlah jenis yang ditemukan dimasing-masing stasiun dipengaruhi oleh kondisi lingkungan pada tiap stasiun. Pada stasiun I ditemukan jumlah jenis yang lebih banyak dibandingkan dengan stasiun lainnya, hal ini dikarenakan pada stasiun I ditemui adanya tumbuhan makrofita akuatik yang hidup di pinggir danau, sehingga memungkinkan adanya sumbangan oksigen yang cukup untuk kehidupan plankton.

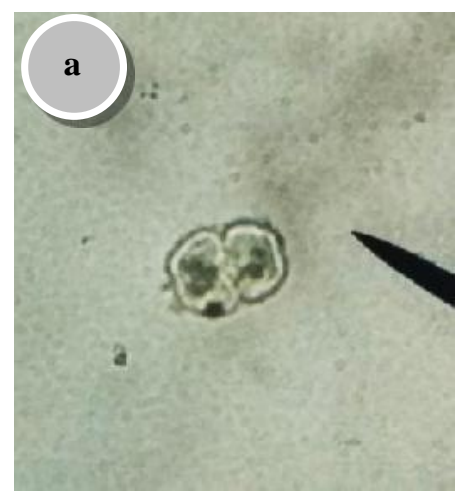

Selain itu stasiun I yang berdekatan dengan daerah penimbunan limbah bonggol sawit memungkinkan terjadinya penambahan bahan organik pada stasiun I. Limbah organik yang kaya akan unsur hara akan menguntungkan bagi pertumbuhan plankton sebagai bahan nutrisi. Hal ini sesuai dengan pernyataan Dix (1981) yang menyatakan bahwa limbah organik yang kaya akan unsur hara akan memicu kenaikan populasi plankton.

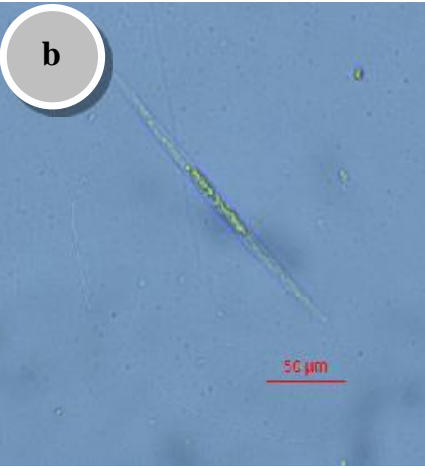

Gambar 3. (a) Cosmarium formulosumdari familyDesmidiaceae(b)Closterium idiosporum dari family Closteriaceae. Selain dari kelas Bacillariophyceae,Kedua spesies dari Kelas Zignematophyceae ini juga banyak ditemukan pada danau bekas tambang.

Hasil pengamatan jenis-jenis Cosmarium formulosum, dan Frustulia plankton yang banyak didapatkan di saxonica.

danau bekas tambang batu bara

Cylindrotheca closterium ini Pangkalan Riau adalah dari jenis merupakan jenis plankton kelas Cylindrotheca closterium, Closterium Bacillariophyceae darifamily idiosporum, Nitzschia longissima, Bacillariaceae. Jenis ini adalah jenis yang banyak ditemukan di danau bekas 
tambang batu bara Desa Pangkalan Riau. Cylindrotheca closterium dapat hidup di zona litoral dan menempel pada permukaan sedimen. Sel bersifat soliter dan motil. Pusat sel berbentuk lancet dengan dua ujung yang tipis dan panjang. Sel kadang kala melengkung atau sigmoid. Nukleus dan kloroplas berada di tengah sel yang berbentuk lanset (Guiry 2011). Mendominasinya jenis Cylindrotheca closterium didanau bekas tambang kemungkinan dipengaruhi oleh kamampuan jenis ini dalam menghasilkan zat allelopati yang dapat menekan pertumbuhan jenis lain sehingga jenis ini mampu bersaing untuk tetap bertahan pada kondisi yang tidak mendukung. Hal ini sesuai dengan pernyataan (Hiromi, 1995) yang menyatakan bahwa jenis Cylindrotheca closterium memiliki dampak berbahaya bagi jenis lain, dimana jenis ini mampu menghasilkan zat allelopati yang dapat menekan pertumbuhan jenis lain.

\section{Closterium idiosporumkelas} Bacillariophyceaemerupakan jenis plankton dari kelas Zignematophyceae family Closteriaceae. Closterium idiosporumtermasuk kedalam jenis acidophiles. Organisme yang mampu bertahan pada kondisi asam tinggi. Sel Closterium idiosporum berbentuk spindle dengan panjang 150-250 $\mu \mathrm{m}$. Sel berbetuk lurus dengan ujung sedikit melengkung atau sigmoid. Hidup pada perairan tawar (John, 2002).

Nitzschia longissima merupakan jenis alga dari kelas Bacillariophyceae family Bacillariaceae. Spesies ini hampir menyerupai Cylindrotheca closterium.Katup berbentuk lancet, dengan ujung yang memanjang. Panjang sel Nitzschia longissima adalah

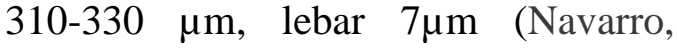
1982)

\section{Cosmarium}

formulosum

merupakan jenis alga kelas Zignematophyceae dari family Desmidiaceae. Alga uniseluler yang umum ditemukan di air tawar. Sel berukuran panjang (51-52 $\mu \mathrm{m})$, luas (40- $42 \mu \mathrm{m})$, isthmus (13-14 $\mu \mathrm{m})$ (Haq, 2012).

Frustulia saxonica. merupakan jenis alga dari kelas Bacillariophyceae familyAmphipleuraceae.Katup umumnya berbentuk rhomboid. Katup simetris untuk kedua sumbu (apikal dan transapikal). Panjang sel (46.5-87.5 $\mu \mathrm{m})$, lebar (12.5-17.5 $\mu \mathrm{m})$ (lange, 2001).

\section{SIMPULAN}

1. Plankton yang diperoleh terdiri dari 23 spesies, 5 kelas dan 14 family. 
Kelas yang didapatkan adalah Bacillariophyceae (7 family, 15 spesies), Chlorophyceae(1 family, 1 spesies), Cyanophyceae(2 family, 2 spesies),Zignematophyceae

family, 3 spesies),Monogonata (2 family, 2 spesies).

2. Jenis-jenis plankton yang banyak didapatkan di danau bekas tambang batu bara Pangkalan Riau adalah dari jenis Cylindrotheca closterium, Closterium idiosporum, Nitzschia longissima, Cosmarium formulosum dan Frustulia saxonica.

\section{DAFTAR PUSTAKA}

AlgaeBase. 2016. AlgaeBase: Listing The World's Algae. www.algaebase.org.Diakses Juli 2018.

Dix, H.M. 1981. Environmental Pollution Atmosphere, Land, Water and Noise. John Willey and Sons. Chischester.

Guiry, M. D. 2011. Cylindrotheca closterium (Ehrenberg) Reimann and Lewin, 1964. http://www.marinespecies.org/ap hia.php? $\mathrm{p}=$ taxdetails\&id=149004. Diakses 22 Juli 2018.

Haq, 2012. Taxonomic Study of Some Cosmarium Species from NorthEastern Areas of Pakistan. Proceedings of the Pakistan Academy of Sciences. 49(3): 181186.
Hiromi, J., Imanishi, D. and Kadota, S.1995. Effectof Cylindrotheca.cl osterium (Bacillariophyceae) on the growth of red-tide raphidophycean. flagellate Hetero sigma akashiwo. Bulletin of the College of Agriculture and Veterinary Medicine, Nihon University. 52: 122-125.

John,2002. The freshwater algal flora of the british isles. Cambridge University Press. United Kingdom.

Kurnia R. 2013. Implementasi Kebijakan Pengelolaan Sektor Pertambangan. Jurnal Demokrasi dan Otonomi Daerah. 11: 1-70.

Lange.-Bertalot, H. (2001). Navicula sensu strict, 10 genera separated from Navicula sensu lato, Frustalia Diatom of Europe 2: 1526.

Navarro JN. 1982. Marine diatoms associated with mangrove prop roots in the Indian River, Florida, U.S.A. Biblio Phycol 61: 1-151.

Raymont, JM. 1984. Plankton dan Produktivitas Bahari. Alih Bahasa oleh Koesobiono. Pascasarjana. Institut Pertanian Bogor.

Reimann, B. E. F. and Lewin, J. C. 1964.Thediatomgenus.Cylindroth eca.Rabenhorst.Journalof the Royal Microscopical Society. 83: 283-296.

Sachlan, M. 1982.Planktonologi. Fakultas Peternakan dan PerikananUniversitasDiponegoro. Semarang. 